\title{
lonizing Radiation Induced Catalysis on Metal Oxide Particles
}

\author{
Pacific Northwest National Laboratory \\ June 1,1997 \\ Progress Report
}

\section{Principal Investigator}

T.A. Fryberger

(509) 375-2709 (Phone)

ta_fryberger@pnl.gov

Pacific Northwest National Laboratory

P.O. Box 999, MSIN K2-20

Richland, WA 99352

\section{Contributors and Collaborators}

Prof. A. Janata

(404) 894-4828 (Phone)

jiri.janata@chemistry.gatech.edu

School of Chemistry and Biochemistry

Georgia Institute of Technology

Atlanta, GA 30332-0400

Prof. M. Alam

(505) 835-5831 (Phone)

alam@nmt.edu

Department of Materials Engineering

New Mexico Tech

Socorro, NM 87801 


\section{Research Objective}

This project focusses on a novel approach for destroying organics found in high-level mixed waste prevalent at DOE sites. In this project we propose that organics can be destroyed by utilizing reduction/oxidation (redox) chemistry resulting from electron-hole $\left(\mathrm{e}^{-} / \mathrm{h}^{+}\right)$pairs generated in stable, wide bandgap semiconductors via interactions with ionizing radiation $(\alpha, \beta, \gamma)$. Conceptually this process is an extension of visible and near-UV photocatalytic processes known to occur at the interfaces of narrow bandgap semiconductors in both solution and gas phases. In these processes, an electron is excited across the energy gap between the filled and empty states in the semiconductor. The excited electron does reductive chemistry and the hole (the point from which the electron was excited) does oxidative chemistry. The energy separation between the hole and the excited electron reflects the redox capability of the $\mathrm{e} / \mathrm{h}^{\mathrm{t}}$ pair, and is dictated by the energy of the absorbed photon and the bandgap of the material. The use of ionizing radiation has advantages in that it i) overcomes optical transparency limitations associated with visible and near-UV illumination (y-rays penetrate much farther into a solution than UV/Vis light), and ii) permits the use of wider bandgap materials (such as $\mathrm{ZrO}_{2}$ ), which possess potentially greater redox capabilities than those with narrow bandgap materials.

Planned experiments are aimed at extending the body of knowledge about e- $/ \mathrm{h}+$ pair chemistry of semiconducting metal oxide (MO) materials by examining the influence of surface structure, defects, and dopants on the photocatalytic activity of narrow bandgap materials $\left(\mathrm{TiO}_{2}\right)$, and by expanding these studies to wider bandgap materials $\left(\mathrm{ZrO}^{2}\right)$ that are virtually unexplored in terms of their e-/ $h+$ pair chemistry. Experiments are being conducted in three areas: 1$) \mathrm{g}$ radiocatalysis of reactant-colloidal metal oxide solutions, 2) photoelectrochemical studies atmodel MO electrodes, and 3) photochemical studies in ultra-high vacuum (UHV) and high pressures on model MO surfaces. An outcome of this proposed work will be a more thorough evaluation of the use of ionizing radiation in the catalytic remediation of organics (and other problem species) in high-level mixed waste.

\section{Research Statement}

High-level radioactive waste storage tanks within DOE sites contain significant amounts of organic components (solid and liquid phases) in the form of solvents, extractants, complexing agents, process chemicals, cleaning agents, and a variety of miscellaneous compounds. These organics pose several safety and pretreatment concerns, particularly for the Hanford tank waste. All currently proposed tank waste cleanup alternatives encounter potential safety and/or pretreatment problems associated with organics. Remediation technologies are needed that significantly reduce the amounts of problem organics without resulting in toxic or flammable gas emissions, and without requiring thermal treatments. These restrictions pose serious technological barriers for current organic destruction methods, which utilize oxidation achieved by thermal or chemical activation. 


\section{Research Progress}

Progress from September 1996 through May 1997 is discussed below in each of the three research areas of the program. The main conclusions thus far are the following:

1. Proof-of-principle results have been reproduced at a different y-facility. These results show a significant radiocatalytic effect for the destruction of EDTA in the presence of colloidal $\mathrm{TiO}_{2}$.

2. An electron scavenger, such as oxygen, is necessary to prevent charge buildup on the $\mathrm{TiO}_{2}$ particles during organic oxidation. However, the inherent dissolved oxygen in solution is of sufficient concentration to preclude the need to bubble oxygen in the solution.

3. As expected, $\mathrm{TiO}_{2}$ is a better oxidative radiocatalyst than $\mathrm{ZrO}_{2}$, but supported noble metals on either oxide do not increase EDTA destruction. This unexpected but fortuitous result indicates that expensive metals may not be necessary in scale-up applications.

4. Electrochemical studies indicate that defects created in the colloidal particle during irradiation may adversely influence charge carrier dynamics in the particle.

5. Vacuum studies indicate that surface defects may promote oxidative photochemistry by bending the semiconductor bands upward, but inhibit reductive photochemistry. However, these same defects may also promote thermal reductive processes.

Details of these and other findings are discussed to a greater extent below.

\section{$\gamma$-Radiocatalysis of Reactant-Colloidal Metal Oxide Solutions}

The proof-of-principle experiments cited in the EMSP proposal for this program were reproduced using a different $\gamma$-facility and an improved experimental setup. These experiments involve the radiocatalytic oxidation of ethylene diamine tetraacetic acid (EDTA), which is a complexing agent found in many of the Hanford waste tanks. Essentially, the current results agree with proof-of-principles studies. An increase in the G-value (defined as the number of events per $100 \mathrm{~V}$ of absorbed energy) for the radiolytic destruction of EDTA was observed in the presence of colloidal $\mathrm{TiO}_{2}$ and $\mathrm{O}_{2}$ over that occurring in aqueous solution (from 2.4 to 3.7). The enhancement is obtained only when both $\mathrm{TiO}_{2}$ and $\mathrm{O}_{2}$ are present in solution.

\section{EDTA Radiocatalysis Studies on $\mathrm{TiO}_{2}$}

- $\mathbf{O}_{2}$ Dependence: The estimated G-values for EDTA radiolysis on $\mathrm{TiO}_{2}$ in the absence of $\mathrm{O}_{2}$ (solution and headspace purged with dry $\mathrm{N}_{2}$ ) are the same as the aqueous solution value (2.4). This indicates that the presence of an electron scavenger ( 0 , in this case) is essential for organic (EDTA) radiocatalytic oxidation. However, special measures for introducing $\mathrm{O}_{2}$, such as bubbling, were not necessary in these experiments because the amount of $\mathrm{O}_{2}$ dissolved in the solution and in the headspace were sufficient for the test batch reactors used. 
- $\mathrm{TiO}_{2}$ Powder Concentration: The G-value for EDTA destruction in colloidal $\mathrm{TiO}_{2}$ solutions is dependent upon the $\mathrm{TiO}_{2}$ powder concentration. This is logical because the absorption of radiation is partitioned between the solution, with its G-value of 2.4 for EDTA destruction, and the $\mathrm{TiO}_{2}$ particles. The overall G-value increases from 3.1 to 3.7 when the $\mathrm{TiO}_{2}$ concentration is increased from 0.05 to $0.10 \mathrm{~g} / \mathrm{ml}$. With a $0.02 \mathrm{M}$ EDTA and $0.10 \mathrm{~g} / \mathrm{ml}$ $\mathrm{TiO}_{2}$ solution, we estimate that $91.5 \%$ of the radiation is absorbed by water, $7.8 \%$ by $\mathrm{TiO}_{2}$, and $0.6 \%$ by EDTA. Therefore, the G-value for EDTA destruction from radiation absorbed by $\mathrm{TiO}_{2}$ is probably considerably higher than the values we estimated based on the overall radiation absorbed.

- Noble Metal Catalysts: Findings indicate that impregnation of the $\mathrm{TiO}_{2}$ catalyst with either a 1\% (by weight) Pd or Pt salt, followed by reduction, had little or no effect on the rate of EDTA destruction versus that obtained in the absence of the metal. In fact, the rate decreased for the Pt case suggesting that the metal's presence may inhibit destruction, either by blocking sites or by trapping holes. No thermal decomposition of EDTA was observed at room temperature in the presence of the metal. This result indicates that expensive noble metals are not necessary for organic oxidation on $\mathrm{TiO}_{2}$ by radiocatalysis.

- Studies with Colloidal $\mathrm{ZrO}_{2}$ : Examination of the destruction of EDTA over colloidal $\mathrm{ZrO}_{2}$ and $\mathrm{Pt} / \mathrm{ZrO}_{2}$ catalysts was begun. Preliminary results indicate that, as expected based on the flat band positions of $\mathrm{ZrO}_{2}$ relative to those of $\mathrm{TiO}_{2}, \mathrm{ZrO}_{2}$ is not as effective as an oxidation catalyst, presumably because valence band holes in $\mathrm{ZrO}_{2}$ are higher lying (less oxidizing). The rate of EDTA destruction on $\mathrm{ZrO}_{2}$ was independent of the presence of Pt, and found to be about $10-20 \%$ less than that of $\mathrm{TiO}_{2}$.

\section{Tetraphenylborate Radiocatalysis Studies}

In an effort to in determine the source of benzene emission during Cs extraction from Savannah River tank wastes, a series of experiments were conducted involving sodium tetraphenylborate (TPB) radiolysis on colloidal $\mathrm{TiO}_{2}$. Because titanates are used in the sorption of $\mathrm{Sr}$ from these wastes, it was thought that radiocatalysis could be a cause of the decomposition of tetraphenylborate to produce benzene. The findings are as follows:

- The rate of TPB destruction by y-irradiation is the same with or without $\mathrm{TiO}_{2}$, and there is no enhancement in the presence of $\mathrm{O}_{2}$. These results suggest that an e-/h+ pair mechanism is not involved in benzene generation, in agreement with results from Savannah River and Georgia Tech.

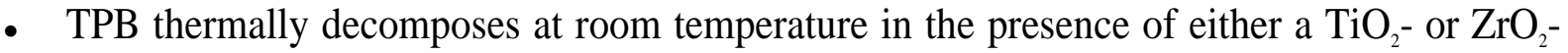
supported Pt catalyst. The product yields (benzene and biphenyl) differ somewhat in the presence or absence of y-radiation, suggesting radiolysis of the thermal products may be taking place. 


\section{Scale-up and Demonstration}

For the radiocatalysis process to be of practical use, catalytic destruction of organics must be demonstrated on a larger scale than the batch reactors used so far. Initial contacts were made with external sources for scale-up reactor work. In particular, informal discussions with Prof. I. Z. Ismagilov of the Boreskov Institiute of Catalysis, Novosibirsk, Russian Federation, and with Alcoa, Inc. have begun. The latter have identified this process as a possible remediation technology for one of their industrial process streams.

\section{Photoelectrochemical and UHV Studies at Model Metal Oxide Electrodes}

To develop an understanding of the similarities and differences between radiolytic chemistry and photochemistry on metal oxide semiconductors, both photoelectrochemical and UHV studies are being carried out on model surfaces. These results will be correlated with the solution studies described above.

\section{Photoelectrochemical Studies}

The effect of Ar sputter damage on the electrochemical response of $\mathrm{TiO}_{2}(110)$ has been examined. Sputter damage, in some sense, may mimic material damage occurring in high radiation fields.

- In agreement with literature results, we have found that reoxidation of sputtered $\mathrm{TiO}_{2}(110)$ with $\mathrm{O}_{2}$ in UHV is straightforward and easily monitored by XPS.

- Mott-Shottky analysis of sputtered and reoxidized $\mathrm{TiO}_{2}(110)$ transferred to solution shows that UHV oxidation still leaves carrier states in the space charge region (200 - $1000 \ddot{A})$. These states may have a significant effect on the efficiency of $\mathrm{e} / \mathrm{h}^{+}$pair separation.

\section{UHV Studies of Chromium Redox Chemistry on $\mathrm{TiO}_{2}$}

Radiocatalysis should not be limited to organic destruction, but should apply to metal redox reactions as well. For this reason we have begun to investigate the chemistry of $\mathrm{CrO}_{2} \mathrm{Cl}_{2}$ on $\mathrm{TiO}_{2}(110)$. The $\mathrm{CrO}_{2} \mathrm{Cl}_{2}$, having $\mathrm{Cr}$ in the $6+$ oxidation state, may be a suitable analog for probing the chemistry of $\mathrm{Cr}(\mathrm{VI})$ species found in Hanford tank wastes.

- $\mathrm{CrO}_{2} \mathrm{Cl}_{2}$ is molecularly adsorbed on $\mathrm{TiO}_{2}(110)$, presumably in a bidentate structure. Work function change measurements indicate the oxygen atoms are bound to the surface and the chlorine atoms extend into vacuum.

- If isolated oxygen vacancies are present on the surface, charge transfer between $\mathrm{CrO}_{2} \mathrm{Cl}_{2}$ and these sites bends the $\mathrm{TiO}_{2}$ bands upward. This effect should drive photo-excited conduction 
band electrons from the surface to the bulk during radiolysis, thus hindering reductive precipitation of $\mathrm{Cr}$ (III) on $\mathrm{TiO}_{2}$. However, the isolated vacancies do not decompose $\mathrm{CrO}_{2} \mathrm{Cl}_{2}$.

- $\mathrm{CrO}_{2} \mathrm{Cl}_{2}$ thermally decomposes on $\mathrm{TiO}_{2}(110)$ above $500 \mathrm{~K}$. The decomposition process involves thermally induced reduction of $\mathrm{Cr}(\mathrm{VI})$ to $\mathrm{Cr}(\mathrm{III})$ via multiple oxygen vacancy sites that are created during $\mathrm{O}_{2}$ desorption, the onset of which is at $500 \mathrm{~K}$.

- Reduced $\mathrm{Cr}$ species are stable on $\mathrm{TiO}_{2}$, and diffuse into the bulk above $750 \mathrm{~K}$.

A study of the reaction of $\mathrm{CrO}_{2} \mathrm{Cl}_{2}$ with water on $\mathrm{TiO}_{2}(110)$ has been completed. These results are currently being analyzed. However, it appears that water reacts with $\mathrm{CrO}_{2} \mathrm{Cl}_{2}$ at $110 \mathrm{~K}$ to eliminate $\mathrm{HCl}$ and form a $\mathrm{Cr}(\mathrm{VI})$-containing oxyanion species on the surface. This species is also reduced by the defects in the oxide, but at a different rate than that of the parent species. The oxyanion chemistry (in the absence of $\mathrm{Cl}$ ) may be a better model than $\mathrm{CrO}_{2} \mathrm{Cl}_{2}$ for probing $\mathrm{Cr}(\mathrm{VI})-\mathrm{Cr}(\mathrm{III})$ chemistry at metal oxide materials.

\section{References}

Su, Y., Y. Wang, J.L. Daschbach, T.B. Fryberger, M.A. Henderson, J. Janata, and C.H.F. Peden, "Gamma-Ray Destruction of EDTA Catalyzed by Titania." J. Adv. Oxid Technol., submitted.

Alam, M., M.A. Henderson, P.D. Kaviratna, G.S. Herman, and C.H.F. Peden, "Chromyl Chloride Chemistry at the $\mathrm{TiO}_{2}(110)$ Surface." J. Phys. Chem. B, submitted. 